\title{
Distinguishing Personality Recognition and Quantification of Emotional Features Based on Users' Information Behavior in Social Media
}

\author{
Chunnian Liu, School of Management, Nanchang University, China \\ Qi Tian, School of Management, Nanchang University, China \\ Mengqiu Chen, School of Management, Nanchang University, China
}

\begin{abstract}
The purpose of this paper is to explore the emotional composition, psychological characteristics, and the consistency between information behavior and attitude of social media users, and to provide reference for online public opinion monitoring, topic detection, and emotional situation evaluation. Based on big-five personality theory and self-difference theory, this paper takes 12,151 Twitter texts during Hurricane Maria as the analysis objects, extracts the personality characteristics of the texts based on convolution neural network, and analyzes the subjectivity and emotional polarity of the texts by Python. Based on the experimental results, this paper analyzes the psychological characteristics and information needs reflected by social media users' information behavior in disaster environment and further verifies and expounds the reasons for the inconsistent information behavior and attitude of social media users in disaster environments.
\end{abstract}

\section{KEYWORDS}

Emotion Classification, Feature Extraction, Online Comment, Personality Traits, Self-Difference

\section{INTRODUCTION}

With the popularity of mobile networks, social media has developed rapidly, people are becoming frequently interested in expressing themselves on social media (Zhou and Jing, 2020), and the academic research on users' psychology has extended to social media. At present, the research on social media users mainly starts from the perspectives of cognition, emotion, personality, behavior, etc. (Gan Chunmei and Liang Xubin, etc., 2018), and the characteristics of social media users have gradually attracted the attention of the academic community. Network events expand their influence through social media platforms, and as social media users, they have strong sociality (Zhang Baosheng and Zhang Qingpu, 2018). Therefore, under the influence of social media platforms, social media users' emotions are stimulated and participate in the dissemination and discussion of public opinion, and 
social media users' emotions and network events overlap each other to jointly drive the emergence and development of network public opinion. In the process of network public opinion dissemination, because the basic reasons of human emotion awakening include expectation, rewards and punishments (Liu Luchuan and Li Xu, etc., 2018), social media users place certain emotional expectations on network events, and while network events are disseminated through social media, their emotional needs are also met (Sharla Cheung and Meng Die et al., 2019). The academic research on emotional communication in social media environment shows that social media users are emotional in the process of discussing and spreading network events, and are easily influenced by their cultural background. Anger, frustration, joy and disgust are more likely to attract the attention of social media users in the process of spreading network events (TenHouten, 2016).

When a disaster occurs, what are the attitudes of bystanders and victims towards the disaster? From the perspective of the characteristics of the public domain, many scholars have found that the public domain is becoming more and more emotional through the study of public culture and media. The specific manifestations are as follows: the frequency of using emotional discourse in the public domain increases, the rise of new media and its strong emotional changes and the public's acceptance of emotional expression increase, so disasters will bring strong emotional atmosphere to ordinary people and victims(Brand and Chisholm et al., 2018); From the perspective of social psychology, researchers have shown that disasters will produce negative emotional reactions (Boyle, 2004; Cohn and Mehl et al., 2004). For example, After the earthquake in Erdoga in 2016, teenagers in the affected areas showed strong depression and anxiety (Gerstner and Lara-Lara et al., 2020); In the survey, Lim, JR, Liu, BF found that tornadoes can cause anxiety and fear (Lim and Liu et al., 2019); During COVID-19, people will have more anxiety and stress emotions (Ocal and CVetkovic et al., 2020); In a survey, McKinzie pointed out that residents in Tuscaloosa and Joplin areas will suffer from pain, sadness and anxiety after suffering from tornadoes (McKinzie, 2018); From the perspective of biological and cultural evolution, Shoemaker thinks that because negative news will increase people's chances of adapting and facing future uncertainty, human beings will naturally pay attention to negative news, and negative emotions such as fear, anger and sadness will trigger human monitoring function (Shoemaker, 1996), so people will pay more attention to information with negative emotions.

Then, when a disaster occurs, do bystanders and victims have the same emotional intensity for the disaster? Elizabeth W. Dunn and Claire Ashton-James pointed out in their research that the death toll related to disasters may have a greater impact on emotional prediction than emotional experience. After a disaster, with the increase of the death toll and the expansion of the influence scope, the victims showed relatively calm emotional performance, while the bystanders showed great emotional fluctuations, which showed that the sad mood increased with the increase of the death toll,the expansion of the disaster scope and the visualization of abstract information (Dunn and Biesanz et al., 2007).

At present, most of the research starts with the cognition of the respondents. After the disaster, the researchers explore the emotional attitude and information needs of the respondents during the disaster through questionnaires, interviews and other methods. But is the cognition of the respondents after the disaster the same as that reflected by the behavior at the time of the disaster? From the perspective of users' information behavior, taking Hurricane Maria as an example, this paper analyzes the information behavior of social media users during the disaster, and explores the psychological characteristics and information needs reflected by social media users' information behavior under the disaster environment. This paper raises the following questions:

RQ1: Under the disaster environment, what kind of psychological characteristics do social media users' information behaviors reflect?

RQ2: What are the characteristics of information needs of social media users in disaster environment?

RQ3: Are social media users' information behaviors consistent with their attitudes in disaster environment? 


\section{RESEARCH DESIGN}

\section{Data Source}

In recent years, due to the characteristics of hurricanes that strong destructiveness and frequent occurrence, scholars from all over the world have paid more and more attention to hurricanes, conducting research on the causes, paths, disaster prevention and emergency management of hurricanes, and continuously improving hurricane response and treatment capacity.

In 2017, the Atlantic Ocean ushered in the most active hurricane season in recent years, and a large number of strong hurricanes were born, among which Hurricane Harvey, Hurricane Emma and Hurricane Maria caused the most serious consequences. Hurricane Maria landed in Puerto Rico on September 20, 2017, causing more than 1,000 deaths. It was the hurricane that caused the most casualties in Puerto Rico's history and caused a catastrophic blow to Puerto Rico. The academic community has conducted research on Hurricane Maria from different angles (Kishore and Marques et al., 2018) (Tian and Zou, 2018) (Lloyd and Rimmer et al., 2019). After Hurricane Maria landed in Puerto Rico, the number of tweets about Hurricane Maria surged, and a large number of users participated in the discussion of Hurricane Maria related topics. Therefore, this paper chose tweets that related to Hurricane Maria as the object to study the emotional and personality characteristics of users in social media environment.

In this paper, Twitter users' tweets within two months after Hurricane Maria are selected as the research object, and the data of Twitter are collected by Python spider. The key words are:' hurricane', Maria', hurricane Maria', hurricane 1: 25 Maria', hurricane Puerto Rico'. The data collection time was from May 20, 2019 to June 5, 2019, and a total of 25,063 tweets were collected. In this paper, the collected data were stored in CVS files according to the forwarding quantity to prepare for data screening. In the stage of data filtering, this paper eliminates duplicate, meaningless or irrelevant tweets, and retains 12,151 tweets as analysis objects. As the likes and forwarding behaviors of social media users also belong to the category of their information behaviors, and the tweets with a large number of likes and forwards also indicate that the opinions and psychological characteristics reflected by the tweets are highly recognized. This paper sorts the tweets according to the number of forwarded and liked, extracts the first 1550 tweets as high-forwarding tweets, and the remaining tweets as ordinary tweets.

\section{Method}

Starting from the information behavior of social media users, this paper analyzes the personality characteristics and emotional tendencies of users reflected by high-forwarding and ordinary tweets after Hurricane Maria, and explores the emotional composition, psychological characteristics, emergency information needs and the consistency of behaviors and attitudes of social media users during disasters. The specific analysis steps are shown in Figure 1.

1. Extraction of personality characteristics from Twitter text. Personality research became a hotspot in personality psychology in 1960s. After that, scholars found that the basic structure of personality was composed of the "Big-Five" factors and became the "Big-Five Personality" (F, 2004). In recent years, the research of Big-Five personality theory has made remarkable progress, which has been regarded by many psychologists as the best paradigm of personality structure. According to the nomenclature of Mc Crea and Costa, the Big-Five factors of personality include Extroversion, Neuroticism, Agreeableness, Conscientiousness and Openness (McCrae).

Data mining is a process of exploring data to find useful knowledge(Wang and Wang, 2008), Convolutional Neural Network (CNN) is one of the most effective methods for data mining(Jiao and Wu et al., 2018). According to the algorithm proposed by Navonil Majumder, Soujanya Poria, etc., which is based on convolution neural network, this algorithm is superior to other algorithms in the 


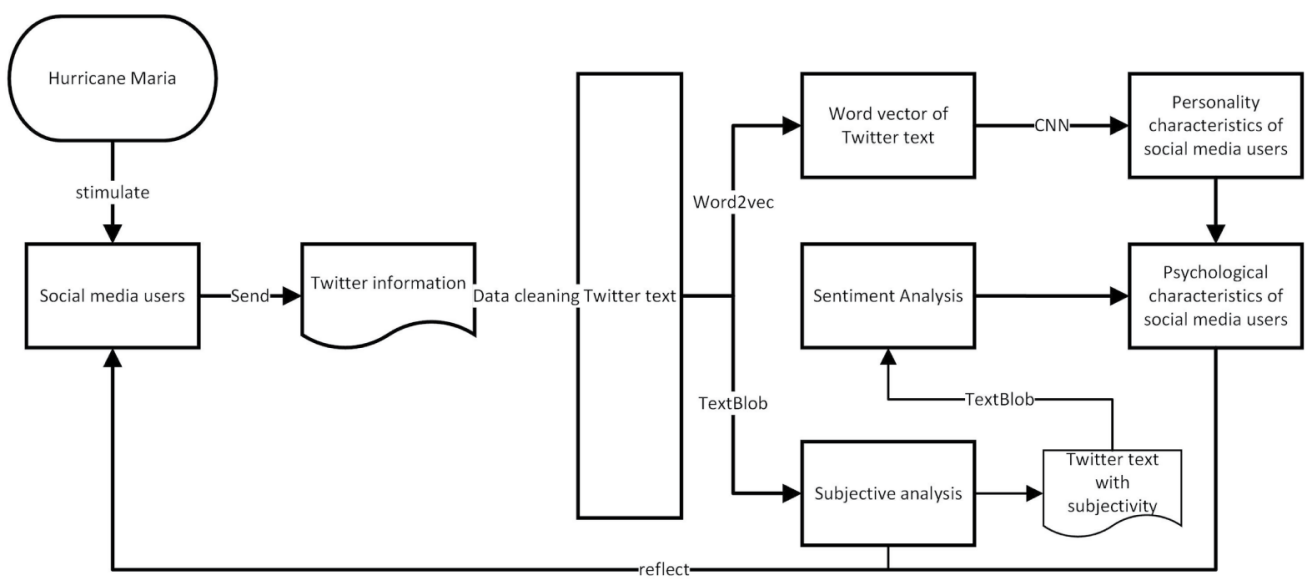

accuracy of personality feature extraction (Majumder and Poria et al., 2017), so this algorithm is selected for text analysis of user comments. In this paper, the Twitter text is processed by Python, and the steps are shown in Figure 2: First, the Twitter text is segmented, the stop words are removed, and all uppercase characters in the text are converted into lowercase characters. The punctuation marks, links and numbers in the tweet are eliminated by regular expressions, and finally the Twitter text is decomposed into a series of words; Secondly, the pre-processed Google Word2vec word vector model is used to convert words into word vectors, and the word vector features are extracted through convolution layer and pooling layer, and the word vectors are combined into sentence vectors; Thirdly, the feature of sentence vector is extracted by convolution layer and pooling layer, and the sentence vector is combined into a single document vector Finally, the tweet feature matrix is constructed through the full connection layer and the judgment result is output.

2. Analysis of text emotional characteristics. Text sentiment analysis, also known as text opinion mining, is a process of analyzing, processing, inducing and reasoning the text, so as to extract the emotional characteristics of subjective text. According to the length of the text, it can be divided into word level, sentence level and document level. Emotional polarity feature analysis can provide useful indicators for different purposes from comments, feedback or criticism.

When analyzing the sentiment polarity of the text, the objective information contained in the text will affect the quality of sentiment analysis, and then affect the research conclusion (Zhao Yanyan and Qin Bing, etc., 2010). Therefore, this paper uses the TextBlob based on NLTK(Natural Language

Figure 2. Text analysis flow of convolutional neural network

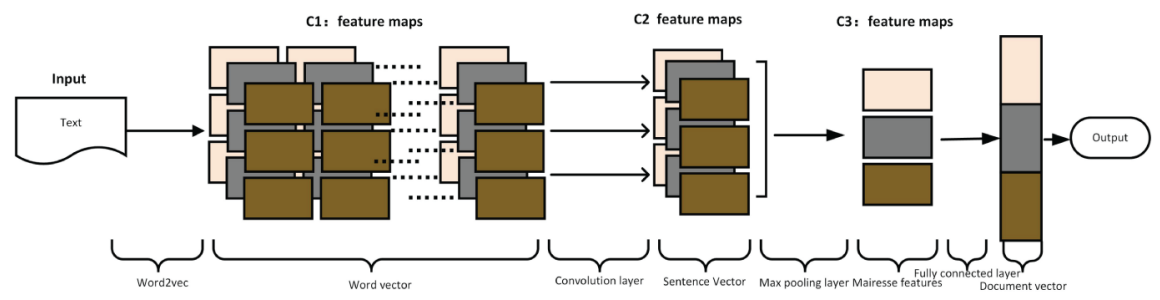


Table 1. Analysis results of personality characteristics of high-forwarding Twitter texts (partial)

\begin{tabular}{|l|c|c|c|c|c|}
\hline \multicolumn{1}{|c|}{ Tweets } & Extroversion & Neuroticism & Agreeableness & Conscientiousness & Openness \\
\hline $\begin{array}{l}\text { Nearly two weeks after Hurricane Maria, 5\% of } \\
\text { Puerto Rico has power, Gov. Rosselló says. }\end{array}$ & 0 & 1 & 0 & 1 & 0 \\
\hline $\begin{array}{l}\text { I've been thinking a lot about all the } \\
\text { Americans_in TX, FL, US Virgin Islands, } \\
\text { Puerto Rico-who are digging out after this yr's } \\
\text { hurricanes. }\end{array}$ & 1 & 0 & 1 & 0 & 0 \\
\hline $\begin{array}{l}\text { You couldn't hit Puerto Rico more squarely. } \\
\text { Maria is centered directly on top of the island. } \\
\text { First Category 4 there since 1932 }\end{array}$ & 1 & 0 & 0 & 0 & 0 \\
\hline $\begin{array}{l}\text { After Hurricane Maria, much of Puerto Rico is } \\
\text { still in the dark }\end{array}$ & 0 & 1 & 0 & 1 & 0 \\
\hline $\begin{array}{l}\text { Tropical Storm Ophelia could reach hurricane } \\
\text { status in a couple of days over the far eastern } \\
\text { Atlantic. }\end{array}$ & 0 & 1 & 0 & 0 & 0 \\
\hline $\begin{array}{l}\text { Puerto Rico schools still closed nearly a month } \\
\text { after hurricane, and students waiting for life to } \\
\text { return to normal. }\end{array}$ & 1 & 1 & 0 & $\ldots$ & 1 \\
\hline$\ldots$ & $\ldots$ & $\ldots$ & $\ldots$ & $\ldots$ \\
\hline
\end{tabular}

Toolkit) and pattern to analyzes the subjectivity of Twitter text by Python, and screens out the subjective Twitter text. The specific steps are as follows: firstly, eliminate the meaningless characters such as punctuation marks, links and numbers in Twitter text by using regular expressions, and perform word segmentation and stop words removal operations on Twitter text, and store the processed files in CSV files; Secondly, the CSV file is imported into the Python program, and the subjectivity of Twitter text is analyzed by using TextBlob; Finally, the objective information is eliminated, and the emotional polarity characteristics of subjective tweets are analyzed by using TextBlob.

\section{ANALYSIS OF RESULTS}

In order to compare and analyze the personality characteristics, emotional tendency and subjective characteristics of high-forwarding and ordinary tweets, we will analyze the high-forwarding and ordinary tweets respectively. In the process of personality analysis, if a certain item in the Big-Five personality is reflected in the tweet, it is marked with 1 , otherwise it is marked with 0 ; In subjective analysis, subjectivity is expressed by the score of interval $[0,1]$. The closer to 0 , the more objective the tweet is, and the closer to 1, the more subjective the tweet is. This article will eliminate tweets with subjective score of 0 ; In the process of emotional polarity analysis, emotional polarity is expressed by the score in the interval $[-1,1]$. If the score is less than 0 , it is negative emotion, if the score is greater than 0 , it is positive emotion, and the closer the score is to -1 or 1 , the stronger the emotional polarity is.

\section{Personality Characteristics of Social Media Users in Disaster Environment}

In this paper, the personality characteristics of high-forwarding and ordinary tweets are analyzed respectively, and some results are shown in Table 1 and Table 2.

In this paper, the personality characteristics reflected by high-forwarding and ordinary tweets are counted, and the results are shown in Table 3 and Figure 3.

Table 3 and Figure 3 show the amount and structure of personality characteristics reflected by high-forwarding and ordinary tweets during Hurricane Maria, respectively. From Table 3 and Figure 3, we can find that neuroticism is the lowest and openness is the highest among personality characteristics reflected by high-forwarding and ordinary tweets, and the distribution of personality 
Table 2. Analysis results of personality characteristics of ordinary Twitter texts (partial)

\begin{tabular}{|l|c|c|c|c|c|}
\hline \multicolumn{1}{|c|}{ Tweets } & Extroversion & Neuroticism & Agreeableness & Conscientiousness & Openness \\
\hline $\begin{array}{l}\text { Soak this in \#puertorico imports 85\% of its } \\
\text { food, going to need a lot of help to prevent } \\
\text { hunger deaths alone }\end{array}$ & 0 & 0 & 1 & 1 & 1 \\
\hline RT for hurricane relief! & 1 & 1 & 0 & 1 & 0 \\
\hline $\begin{array}{l}\text { Puerto Rico governor ahead of \#Maria: } \\
\text { "We have not experienced an event of this } \\
\text { magnitude in our modern history }\end{array}$ & 1 & 0 & 1 & 1 & 1 \\
\hline $\begin{array}{l}\text { Not Again: Another Hurricane Targeting the } \\
\text { Gulf Coast. }\end{array}$ & 1 & 1 & 0 & 0 & 1 \\
\hline $\begin{array}{l}\text { Hurricane Ophelia has turned Scotland's } \\
\text { skies a strange and eerie shade }\end{array}$ & 0 & 0 & 0 & 0 & 0 \\
\hline $\begin{array}{l}\text { The big 3 of 2017 making U.S. landfall at } \\
\text { Category 4 strength }\end{array}$ & 1 & 0 & $\ldots$ & $\ldots$ & $\ldots$ \\
\hline$\ldots$ & $\ldots$ & $\ldots$ & $\ldots$ & 0 \\
\hline
\end{tabular}

Table 3. Personality characteristics of social media users

\begin{tabular}{|l|l|l|l|l|l|l|}
\hline \multirow{2}{*}{} & \multicolumn{3}{|c|}{ Ordinary Tweets } & \multicolumn{3}{c|}{ High-Forwarding Tweets } \\
\cline { 2 - 7 } & \multicolumn{1}{|c|}{ Amount } & \multicolumn{1}{|c|}{ Average } & \multicolumn{1}{|c|}{ Percentage } & Amount & Average & Percentage \\
\hline Extroversion & 5507 & 0.52 & $51.71 \%$ & 802 & 0.53 & $53.47 \%$ \\
\hline Neuroticism & 5372 & 0.50 & $50.44 \%$ & 760 & 0.51 & $50.67 \%$ \\
\hline Agreeableness & 5546 & 0.52 & $52.08 \%$ & 809 & 0.54 & $53.93 \%$ \\
\hline Conscientiousness & 5439 & 0.51 & $51.07 \%$ & 805 & 0.54 & $53.67 \%$ \\
\hline Openness & 5547 & 0.52 & $52.08 \%$ & 811 & 0.54 & $54.07 \%$ \\
\hline
\end{tabular}

Figure 3. Personality structure of Twitter text

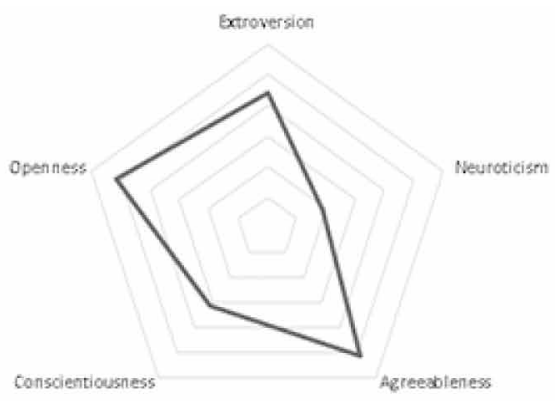

(A) OROINARY TWITTER TEXTS

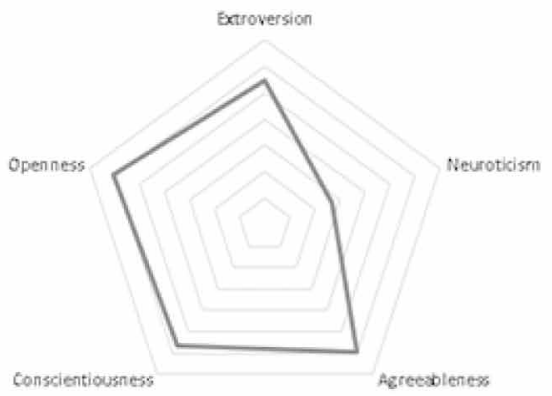

(B) HIGH-FORWARDING TWITTER TEXTS

characteristics reflected by the two tweets is similar, reflecting the overall personality characteristics structure of social media users under disaster background. In the personality characteristics reflected by highly forwarded tweets, the frequency of conscientiousness is significantly higher than that of ordinary tweets, which reflects that conscientiousness can enhance the recognition of individuals in social media under the disaster environment. 
Table 4. Subjectivity of Twitter Text after Disaster

\begin{tabular}{|l|l|l|l|l|l|}
\hline & \multicolumn{1}{|c|}{ Subjectivity $=\mathbf{0}$} & $\mathbf{0}<$ Subjectivity $<\mathbf{1}$ & Subjectivity =1 & \multicolumn{1}{|c|}{ Average } & \multicolumn{1}{c|}{ Median } \\
\hline ordinary tweets & $4607(43.26 \%)$ & $5563(52.23 \%)$ & $480(4.51 \%)$ & 0.28 & 0.2 \\
\hline $\begin{array}{l}\text { high-forwarding } \\
\text { tweets }\end{array}$ & $654(42.19 \%)$ & $812(52.39 \%)$ & $84(5.42 \%)$ & 0.29 & 0.2 \\
\hline
\end{tabular}

\section{Emotional Characteristics of Social Media Users in Disaster Environment}

In this paper, the subjective analysis of high-forwarding and ordinary tweets during Hurricane Maria is conducted, and the results are shown in Table 4 and Figure 4.

From Table 4 and Figure 4, it can be found that the subjective score structure of high-forwarding and ordinary tweets during Hurricane Maria is similar, with score between objective and subjective accounting for the main body, followed by completely objective tweets(Subjectivity=0), accounting for about $43 \%$, and completely subjective tweets (Subjectivity =1)accounting for the lowest proportion, accounting for about $5 \%$, indicating that social media users tend to publish and seek relatively objective disaster emergency information during Hurricane Maria.

Since objective text (Subjectivity $=0$ ) information will affect text emotional polarity analysis, this paper will eliminate Twitter texts with subjective score of 0 during Hurricane Maria, and analyze the emotional polarity characteristics of the remaining texts.

This paper analyzes the emotional polarity characteristics of social media users reflected by highforwarding and ordinary tweets during Hurricane Maria. The results are shown in Table 5 and Figure 5.

Table 5 and Figure 5 show the results and structure of emotional polarity characteristics reflected by high-forwarding and ordinary tweets during Hurricane Maria. From Table 5 and Figure 5, we can find that: Firstly, the overall structure of emotional polarity of high forwarding tweets is similar to that of ordinary tweets, which shows that positive tweets account for the highest proportion, higher than $50 \%$ of the total sample, negative tweets account for the second, about $32 \%$, and neutral tweets account for the lowest, about $13 \%$. During the disaster, social media users were generally positive.

Figure 4. Subjective feature structure of Twitter text

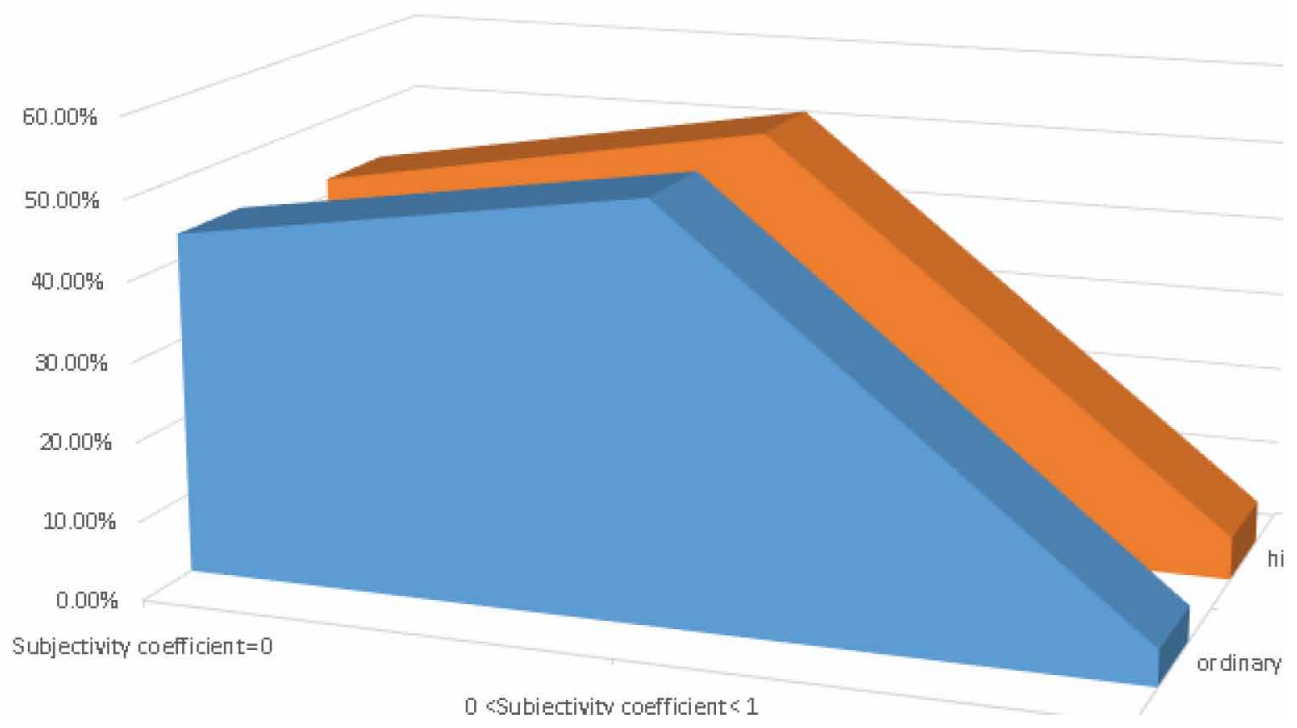


Table 5. Analysis results of emotional polarity characteristics of Twitter text

\begin{tabular}{|l|l|l|l|l|l|l|l|c|}
\hline & \multicolumn{4}{|c|}{ Ordinary Tweets } & \multicolumn{5}{c|}{ High-Forwarding Tweets } \\
\cline { 2 - 10 } & \multicolumn{1}{|c|}{ Amount } & Percentage & Average & Median & Amount & Percentage & Average & Median \\
\hline Positive & 3395 & $56.18 \%$ & 0.29 & 0.25 & 479 & $53.46 \%$ & 0.29 & 0.25 \\
\hline Negative & 1889 & $31.26 \%$ & -0.27 & -0.19 & 297 & $33.15 \%$ & -0.28 & -0.17 \\
\hline Neutral & 759 & $12.56 \%$ & 0 & 0 & 120 & $13.39 \%$ & 0 & 0 \\
\hline
\end{tabular}

Figure 5. Emotional polarity feature structure of Twitter text

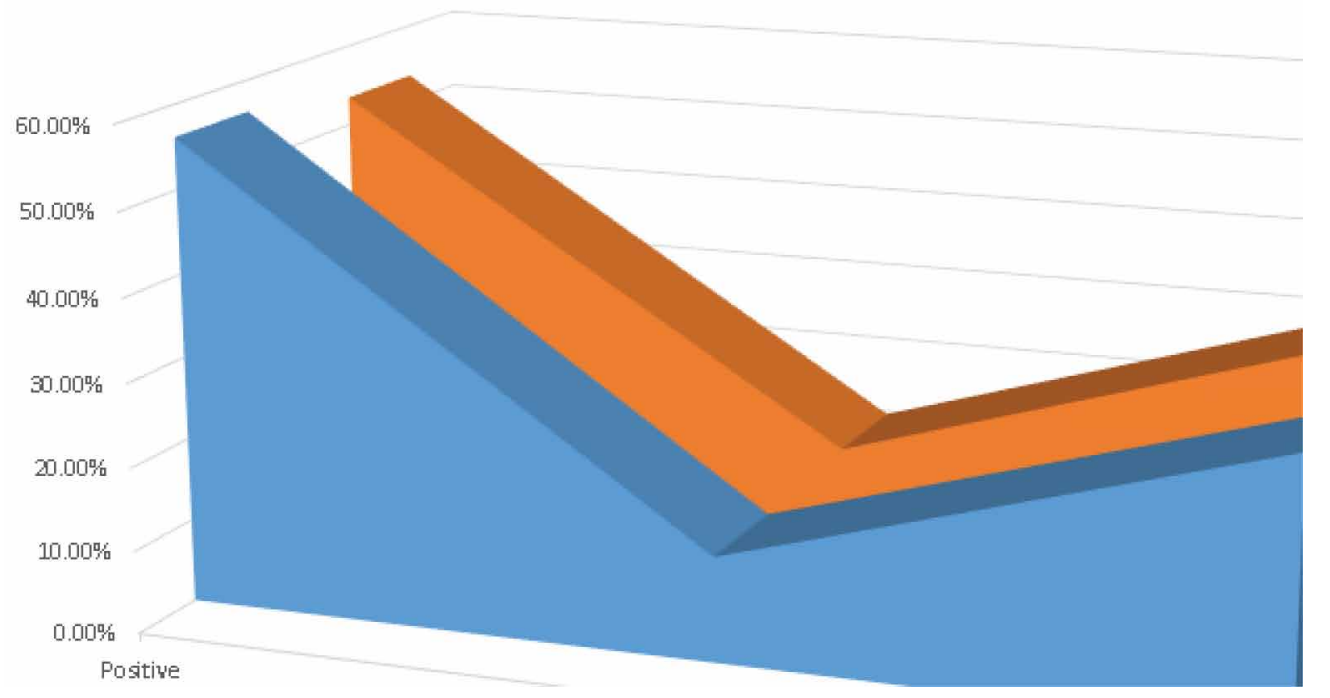

Secondly, high-forwarding tweets show more negative emotions, while ordinary tweets show more positive emotions. Information containing negative emotions is easier to spread in disaster environment.

\section{DISCUSSION}

This paper analyzes the information behavior of social media users during Hurricane Maria, analyzes the psychological and emotional characteristics reflected by their information behavior and the information structure of social media during the disaster. We find that:

\section{RQ1: Under the Disaster Environment, What Kind of Psychological Characteristics Do Social Media Users' Information Behaviors Reflect?}

Personality has great influence on people's behavior, which has been studied by many scholars. For example, Hurtz, G M, Donovan, J J analyzed the influence of personality on job performance from the perspective of job performance (Hurtz and Donovan, 2000); O'Connor, MC, Paunen, SV analyzed the relationship between personality characteristics and academic performance ( $\mathrm{O}^{\prime}$ Connor and Paunen, 2007); Karim, NSA, Zamzuri and NHA put forward that there is a significant correlation between personality characteristics and immoral network behaviors of college students such as fraud, plagiarism, forgery and illegality (Karim and Zamzuri et al., 2009). Different personality characteristics have certain influence on the network behavior of network users. The information seeking and spreading 
behavior of network users on social media platforms after disasters also belongs to the information behavior of users, which is related to their personality characteristics.

Through the experimental results of this paper, combined with the Big-Five personality theory, we can find that openness accounts for the highest proportion in the personality characteristics of postdisaster Twitter messages, and the higher proportion of these characteristics indicates that individuals are imaginative and seek change, and have the characteristics of imagination, aesthetics, emotion, diversity and creativity, indicating that social media users actively search and disseminate disaster information after the disaster, and the research results show that neuroticism accounts for the lowest proportion. And this feature reflects the differences in individuals' experience distress, as well as the differences in cognition and behavior style of this difference. Its relatively low proportion indicates that social media users are less affected by anxiety, anxiety, depression and other factors after the disaster, and are more likely to pay attention to positive events. This confirms with Neubaum, G, Rosner, L, etc. that users' active participation in social media communication will ease their emotions (Neubaum and Roesner et al., 2014). In addition, extroversion reflects the characteristics of individual communication enthusiasm, rich feelings and optimism; Pleasantness reflects the characteristics of individual trust, altruism and frankness; Conscientiousness reflects the characteristics of individual conscientiousness, reliability, caution, etc. The above statistical results show that the percentage difference of these three characteristics is small and between the maximum and minimum, which indicates that Twitter users have the above characteristics after the disaster, but the characteristics are not obvious. At the same time, through the analysis of emotional polarity characteristics of Twitter texts during Hurricane Maria, it can be found that high-forwarding Twitter texts and ordinary Twitter texts show similar proportions, and the overall performance is that neutral texts account for only about $13 \%$ of subjective texts, and the rest are emotional texts, which indicates that social media users tend to show emotional characteristics when expressing their views in disaster environment, while tweets with positive emotional characteristics are dominant in emotional texts. Tweets with negative emotional characteristics come second, but the proportion of tweets with positive emotions is obviously different from that of tweets with negative emotions, which indicates that social media users show more relatively positive emotions in disaster environment.

Therefore, this paper holds that during the disaster, social media users have the following characteristics: (1) After the disaster, social media users are full of imagination, seek for change, and have positive information seeking and dissemination behavior, which will promote the rapid dissemination of disaster-related information; (2) After the disaster, social media users are less affected by anxiety and uneasiness, and are more likely to pay attention to more positive emergency information; (3) During Hurricane Maria, the high-forwarding and ordinary tweets reflected a great difference in the proportion of sense of conscientiousness. This paper thinks that the high-forwarding tweets already have the basic opinion leader characteristics. The research of Song, SY, Cho, E shows that openness, trust, expressionism and ability in interpersonal relationships will significantly enhance the individual's opinion leadership tendency in social media (Song and Cho et al., 2017), so we believe that the sense of conscientiousness in personality characteristics will also be to a certain extent.

\section{RQ2: What are the Characteristics of Information Needs of Social Media Users in Disaster Environment?}

Analyzing the characteristics of social media users' information needs in disaster environment can help researchers discover the law of social media information dissemination after disaster, gain insight into the current situation of social media users' emergency information needs, and improve the efficiency of emergency response and emergency information dissemination, which has certain practical significance. Through the analysis of Twitter text during Hurricane Maria, we can find that the emotional needs of social media users have the following characteristics in disaster environment: 
1. After disasters, social media users tend to trust objective information more. Through the subjective analysis of Twitter text during Hurricane Maria, we can find that the ratio of objective text (subjective coefficient is zero) in Twitter text is about $43 \%$ during the disaster, and the ratio of high-forwarding is similar to that of objective text in ordinary text, which indicates that social media users need to express objective information such as disaster harm degree, travel route and preventive measures during the disaster, and social media users are willing to publish, disseminate and discuss objective information about disasters.

2. For subjective information, social media users are more willing to publish, spread and receive that with obvious emotions than neutral information, and have higher demand for information with positive emotions. Through subjective and emotional polarity analysis of Twitter text during Hurricane Maria, this paper finds that tweets with non-zero subjective coefficient account for about $60 \%$ of the main body in subjective analysis, which indicates that social media users are more willing to spread subjective emergency information than objective information; In the analysis of emotional polarity of subjective texts, it is found that the information with positive emotional polarity accounts for the most, while the information with neutral emotional polarity accounts for less, which indicates that social media users are more willing to spread emotional information in disaster environment, which is consistent with relevant academic research, for example, Stieglitz, Dang-Xuan's analysis of presidential election information in social media, It is concluded that the higher the "total amount" of emotions (the sum of absolute values of positive emotions and negative emotions) contained in information, the more forwarding times and the faster forwarding speed (Stieglitz and Dang-Xuan, 2013); Tsugawa S, Ohsaki H found that tweets with emotional characteristics are easier to forward and spread faster (Tsugawa S, 2017).

\section{RQ3: Are Social Media Users' Information Behaviors Consistent With Their Attitudes in Disaster Environment?}

Through the analysis of social media information during Hurricane Maria, it can be found that social media users' information behavior reflects their relatively positive attitude in the face of disasters, and users are less affected by anxiety, uneasiness and other emotions, with low subjective coefficient and relatively stable emotions. However, related academic research believes that the public sphere is increasingly showing emotional characteristics in disaster environment, and disaster events will produce negative emotional reactions and cause large emotional fluctuations of bystanders. Therefore, this paper holds that there are obvious differences between social media users' information behaviors and attitudes when disasters occur. This paper argues that the main reasons for this phenomenon include:

1. According to the theory of self-difference, when individuals express their views and attitudes in real life, they will be restricted by moral and legal factors, while in social media environment, users can freely share their views on events. Higgins put forward the theory of self-difference in 1987, which holds that the individual self consists of three parts: ideal self, due self and real self, among which the real self represents the characteristics that individuals or others think individuals actually possess; Ideal self represents the characteristics that individuals or others want individuals to have; Self should represent the characteristics that individuals or others think that individuals have obligations or responsibilities (Higgins, 1987). Based on the self-difference theory $\mathrm{Hu}$,Chunan put forward the advanced self-difference theory, which takes the true self representing the internal characteristics, thoughts, beliefs and consciousness of individuals as the fourth field of individual self. He believes that the real self is an important part of the self-behavior guidance of individuals in unconscious environment (Hu and Kumar 
et al., 2017). Rogers believes that individuals tend to show their real self in real-life social interaction, but when the real self-conflicts with the supposed self, in order to avoid being criticized by morality or sanctioned by law, individuals usually choose to hide some attributes of their real selves $(C, 1951)$. For example, McKenna KYA and Bargh JA mentioned in their research that due to the limitations of moral and legal norms in the real world, marginalized believers (such as homosexuals, etc.) cannot fully express their views and thoughts in realworld communication (McKenna KYA, 1998).

According to the theory of self-difference, in the real environment, when individuals face disasters, their attitudes and opinions are limited by morality, law and belief in the real world. Therefore, individual experience chooses to hide some attributes of the real self and show the attributes of the self. Social media platform can provide users with a unique environment. In such an environment, users can freely express their attitudes towards events without worrying about being bound by the real-world environment. Therefore, users' information behavior on social media platforms may have different attitudes towards disasters than those in the real world.

2. The psychological characteristics reflected by the survey of the public before and after the event reflect more explicit attitude than implicit attitude. According to relevant academic research, self-report only expresses explicit attitude, while implicit attitude needs to be expressed under cognitive pressure or by other means (T, 2004). When the explicit attitude is inconsistent with implicit attitude, individual behavior is directly affected by implicit attitude in most cases. Nowadays, most researches start with individual self-expression and self-report, and study their psychological characteristics. For the public, when expressing their attitude to the outside world, they will be constrained by social culture, morality and other conditions, and will consciously hide the attitude that does not conform to social morality. Therefore, it is difficult to obtain users' invisible attitude towards disasters, which leads to inaccurate measurement of users' psychological characteristics and errors in predicting users' information behavior.

3. Human beings deal with information through two different information systems, and there are some differences in the way people deal with information in different environments. Therefore, the attitude of the public towards disasters obtained from the survey is different from the psychological characteristics reflected by the public when facing disasters. According to Epstein's cognitive-empirical self theory (CEST) (Epstein, 1994), human beings understand information through two different information processing systems, and people's predicted emotional response in the face of a certain disaster in the future is often different from the emotional tendency in the face of a disaster (Wilson and Wheatley et al., 2000; Dunn, 2006), and different emotional tendencies in the face of disaster will affect people's information behavior. We think that the reason for the inconsistency between attitude and behavior may be that emotional prediction based on attitude and emotional experience in the face of disaster may be driven by different information processing modes. According to Epstein's Cognitive-Empirical Self Theory (CEST)(Epstein, 1994), human beings understand information through two different information processing systems, one of which is good at dealing with abstract symbols, words and numbers, which relies on rationality but reacts slowly, and the other is good at dealing with concrete images, narratives and metaphors, which relies on experience but reacts quickly (Chaiken, 1999). As for emotional prediction, people use information processing systems to process different forms of information in different environments, and the results are not the same. Therefore, this is one of the reasons why the public's psychological characteristics for disasters are different from those reflected by information behaviors in the face of disasters. 


\section{CONCLUSION}

Starting from the information behavior of social media users, this paper discusses the the psychological characteristics, information demand characteristics and the relationship between the behaviors and attitudes of social media users under disaster environment. This paper intends to make four contributions to the literature.

First of all, many previous studies have explored the psychological characteristics of victims and bystanders through post-disaster investigation. They believe that people express more of their emotions in public occasions after disasters, while disasters bring strong negative emotions to ordinary people. However, when a disaster occurs, it is not clear what kind of psychological characteristics will be reflected by the information behavior of victims and bystanders. Therefore, this paper uses the methods of Convolutional Neural Network (CNN) and text analysis of emotions to analyze the information behavior of social media users when disasters occur. Compared with using the method of post-disaster surveys, Convolutional Neural Network (CNN) and text analysis can analyze the unconscious behavior of social media users during a disaster, so as to more accurately describe their psychological characteristics in a disaster environment, We found that: (1) After disasters, social media users become richer in imagination and more inclined to seek changes, and have active information seeking and dissemination behavior, which will promote the rapid dissemination of disaster related information; (2) after disasters, social media users are less affected by anxiety, and they are more likely to pay more attention to positive emergency information; (3) Conscientiousness of personality characteristics enhances the individual opinion leadership tendency.

Secondly, many previous studies used questionnaires and interviews to explore the information needs of social media users after disasters. It is believed that after the disaster, people will pay more attention to information of negative emotions in order to cope with the uncertainty in the future. However, in the social media environment, it is still unknown whether social media users need emergency information with negative emotions. Therefore, this paper directly explores the spreading result of disaster information itself to study the characteristics of users' information needs after disasters. Compared with the traditional methods of questionnaire and interview, Convolutional Neural Network (CNN) and text analysis of emotions can further eliminate subjective factors in the research process. Through the analysis, we found that (1) After disasters, social media users tend to trust objective information more; (2) For subjective information, social media users are more willing to publish, spread and receive that with obvious emotions than neutral information, and have higher demand for information with positive emotions.

Thirdly, previous studies have found that both victims and bystanders are negative in terms of their attitudes toward disasters, and with the expansion of disasters, individuals show more emotional fluctuations. However, it is still unclear whether the conclusions are consistent in the social media environment. In this paper, with the methods of Convolutional Neural Network (CNN) and text analysis of emotions, which effectively avoid the subjective influence of users' emotional changes after disasters, we found that social media users have a relatively positive attitude towards disaster, and they are less affected by anxiety and other emotions, and their emotions are relatively stable.

Finally, this paper expands previous interpretation models in the following three aspects: (1) According to the theory of self-difference, individuals will be restricted by moral and legal factors when expressing their views and attitudes in real life environment, while users can freely share their views in a social media environment; (2) Previous investigations of the public reflect people's explicit attitudes rather than implicit attitudes, and the latter can be expressed only under pressure or by other means; (3) People have two different recognitive systems to deal with information, and the way people deal with information differs according to environments. Therefore, the post-disaster survey results of people's attitudes towards disasters are different from the psychological characteristics people show when they are facing disasters. 
In brief, this paper uses Convolutional Neural Network (CNN) and text analysis of emotions to analyze the information behavior of social media users after disasters. Compared with the traditional research methods, our methods effectively avoid the subjective factors in the research and the influence of the change in attitudes after the disasters. The results of this paper supplement the existing literature, so that the research on the psychological characteristics of victims and bystanders in the disaster environment extends to the field of social media. At the same time, this paper also expands previous interpretation models to enrich theoretical research. This study's conclusions provide reference for future studies in social media user portrait, user emergency information needs, emergency information dissemination and other relative fields.

\section{LIMITATION}

It is an important work with theoretical and practical significance to study the emotional polarity of social media and users' personality characteristics. We believe that there are still some shortcomings in this study, which are as follows: (1) Due to certain restrictions, we only studied the Twitter information characteristics during Hurricane Maria, and did not further expand the social media information sources. Future research can further expand the information sources and extract and analyze the information characteristics in other social media; (2) taking hurricane Maria as an example, this paper did not further study the social media information during other types of disasters, and future research can compare the social media information characteristics during different types of disasters. (3) We chose the neural network algorithm proposed by Navonil Majumder and Soujanya Poria to extract the personality characteristics reflected by social media information, without comparing the analysis results of other algorithms. Future research can compare the analysis results of different algorithms for social media information characteristics during disasters.

\section{FUNDING BODY}

This research is supported by: National Natural Science Foundation of China (project number: 71663038 and 72064027); Educational Science Planning Project in Jiangxi Province (project number: 18YB011). 


\section{REFERENCES}

Boyle, M. P. S. M., Schmierbach, M., Armstrong, C. L., McLeod, D. M., Shah, D. V., \& Pan, Z. (2004). Information seeking and emotional reactions to the September 11 terrorist attacks. Journalism \& Mass Communication Quarterly, 81(1), 155-167. doi:10.1177/107769900408100111

Brand, R. M., Chisholm, K., Terhaag, S., Lau, W., Forbes, D., Holmes, A., \& O’Donnell, M. (2018). Understanding the Early Support Needs of Survivors of Traumatic Events: The Example of Severe Injury Survivors. Psychological Trauma: Theory, Research, Practice, and Policy, 10(3), 376-385. doi:10.1037/tra0000274 PMID:28557484

C, R. (1951). Client-centered therapy. Houghton Mifflin.

Chaiken, S. T. Y. (1999). Dual-process theories in social psychology. Guilford Press.

Cheung \& Meng. (2019). The formation mechanism of dropout behavior of social media users with strong relationship under the framework of S-O-R analysis-an exploratory study based on grounded theory. Information Theory and Practice, 42(7), 80-85+112.

Cohn, M. A., Mehl, M. R., \& Pennebaker, J. W. (2004). Linguistic markers of psychological change surrounding September 11, 2001. Psychological Science, 15(10), 687-693. doi:10.1111/j.0956-7976.2004.00741.x PMID: 15447640

Dunn, E. W., Biesanz, J. C., Human, L. J., \& Finn, S. (2007). Misunderstanding the affective consequences of everyday social interactions: The hidden benefits of putting one's best face forward. Journal of Personality and Social Psychology, 92(6), 990-1005. doi:10.1037/0022-3514.92.6.990 PMID:17547484

Dunn, E. W. L. S. (2006). Hearts and minds: Affective influences on social cognition and behavior. Psychology Press.

Epstein, S. (1994). Integration of the cognitive and the psychodynamic unconscious. The American Psychologist, 49(8), 709-724. doi:10.1037/0003-066X.49.8.709 PMID:8092614

F, R. M. B. B. (2004). Five-Factor Model of Personality and Career Exploration. Journal of Career Assessment, 12(3), 223-238.

Gan, C., \& Liang, X. (2018). A Review of Social Network User Behavior Research from the Perspective of Usage and Satisfaction: Content Analysis Based on 54 Foreign Empirical Research Documents. Library and Information Work, 62(07), 134-143.

Gerstner, R. M. F., Lara-Lara, F., Vasconez, E., Viscor, G., Jarrin, J. D., \& Ortiz-Prado, E. (2020). Earthquakerelated stressors associated with suicidality, depression, anxiety and post-traumatic stress in adolescents from Muisne after the earthquake 2016 in Ecuador. BMC Psychiatry, 20(1), 347. doi:10.1186/s12888-020-02759-x PMID:32616034

Goenjian, A. K., Molina, L., Steinberg, A. M., Fairbanks, L. A., Alvarez, M. L., Goenjian, H. A., \& Pynoos, R. S. (2001). Posttraumatic stress and depressive reactions among Nicaraguan adolescents after hurricane mitch. The American Journal of Psychiatry, 158(5), 788-794. doi:10.1176/appi.ajp.158.5.788 PMID:11329403

Higgins, E. T. (1987). Self-Discrepancy: A Theory Relating Self and Affect. Psychological Review, 94(3), 319-340. doi:10.1037/0033-295X.94.3.319 PMID:3615707

Hu, C., Kumar, S., Huang, J., \& Ratnavelu, K. (2017). Disinhibition of negative true self for identity reconstructions in cyberspace: Advancing self-discrepancy theory for virtual setting. PLoS One, 12(4, e01756234), e0175623. doi:10.1371/journal.pone.0175623 PMID:28399153

Hurtz, G. M., \& Donovan, J. J. (2000). Personality and job performance: The Big Five revisited. The Journal of Applied Psychology, 85(6), 869-879. doi:10.1037/0021-9010.85.6.869 PMID:11125652

Hussain, A., Weisaeth, L., \& Heir, T. (2011). Psychiatric disorders and functional impairment among disaster victims after exposure to a natural disaster: A population based study. Journal of Affective Disorders, 128(1-2), 135-141. doi:10.1016/j.jad.2010.06.018 PMID:20619900

Jiao, L., Wu, H., Bie, R., Umek, A., \& Kos, A. (2018). Towards Real-Time Multi-Sensor Golf Swing Classification Using Deep CNNs. Journal of Database Management, 29(3), 17-42. doi:10.4018/JDM.2018070102 
Karim, N. S. A., Zamzuri, N. H. A., \& Nor, Y. M. (2009). Exploring the relationship between Internet ethics in university students and the big five model of personality. Computers \& Education, 53(1), 86-93. doi:10.1016/j. compedu.2009.01.001

Kishore, N., Marques, D., Mahmud, A., Kiang, M. V., Rodriguez, I., Fuller, A., Ebner, P., Sorensen, C., Racy, F., Lemery, J., Maas, L., Leaning, J., Irizarry, R. A., Balsari, S., \& Buckee, C. O. (2018). Mortality in Puerto Rico after Hurricane Maria. The New England Journal of Medicine, 379(2), 162-170. doi:10.1056/NEJMsa1803972 PMID:29809109

Kubey, R. W. P. T., \& Peluso, T. (1990). Emotional response as a cause of interpersonal news diffusion: The case of the space shuttle tragedy. Journal of Broadcasting \& Electronic, 34(1), 69-76. doi:10.1080/08838159009386726

Lim, J. R., Liu, B. F., Egnoto, M., \& Roberts, H. A. (2019). Individuals' religiosity and emotional coping in response to disasters. Journal of Contingencies and Crisis Management, 27(4), 331-345. doi:10.1111/14685973.12263

Liu \& Xu. (2018). A Review of the Research on Negative Emotion and Negative Use Behavior of Social Media Users. Journal of Information, 37(1), 105-113+121.

Lloyd, J. D., Rimmer, C. C., \& Salguero-Faría, J. A. (2019). Short-term effects of hurricanes Maria and Irma on forest birds of Puerto Rico. PLoS One, 14(6, e02144326), e0214432. doi:10.1371/journal.pone.0214432 PMID:31185024

Majumder, N., Poria, S., Gelbukh, A., \& Cambria, E. (2017). Deep Learning-Based Document Modeling for Personality Detection from Text. IEEE Intelligent Systems, 32(2), 74-79. doi:10.1109/MIS.2017.23

McCrae, R. R. J. O., \& John, O. P. (1992, June). An introduction to the five - factor model and its applications. Journal of Personality, 60(2), 175-215. doi:10.1111/j.1467-6494.1992.tb00970.x PMID:1635039

McKenna, K. Y. A., \& Bargh, J. A. (1998). Coming out in the age of the Internet: Identity "demarginalization" through virtual group participation. Journal of Personality and Social Psychology, 75(3), 681-694. doi:10.1037/0022-3514.75.3.681

McKinzie, A. E. (2018). In their own words: Disaster and emotion, suffering, and mental health. International Journal of Qualitative Studies on Health and Well-being, 13(14401081), 1440108. doi:10.1080/17482631.20 18.1440108 PMID:29493424

Neubaum, G., \& Roesner, L. (2014). Psychosocial functions of social media usage in a disaster situation: A multi-methodological approach. Computers in Human Behavior, 34, 28-38. doi:10.1016/j.chb.2014.01.021

O’Connor, M. C., \& Paunonen, S. V. (2007). Big five personality predictors of post-secondary academic performance. Personality and Individual Differences, 43(5), 971-990. doi:10.1016/j.paid.2007.03.017

Ocal, A., Cvetkovic, V. M., Baytiyeh, H., Tedim, F. M. S., \& Zečević, M. (2020). Public reactions to the disaster COVID-19: A comparative study in Italy, Lebanon, Portugal, and Serbia. Geomatics, Natural Hazards \& Risk, 11(1), 1864-1885. doi:10.1080/19475705.2020.1811405

Shoemaker, P. (1996). Hardwired for news: Using biological and cultural evolution to explain the surveillance function. Journal of Communication, 46(3), 32-47. doi:10.1111/j.1460-2466.1996.tb01487.x

Song, S. Y., Cho, E., \& Kim, Y.-K. (2017). Personality factors and flow affecting opinion leadership in social media. Personality and Individual Differences, 114, 16-23. doi:10.1016/j.paid.2017.03.058

Stieglitz, S., \& Dang-Xuan, L. (2013). Emotions and Information Diffusion in Social Media-Sentiment of Microblogs and Sharing Behavior. Journal of Management Information Systems, 29(4), 217-247. doi:10.2753/ MIS0742-1222290408

T, F. S. (2004). Social Being: A Core Motive Approach to Social Psychology. John Wiley \& Sons.

TenHouten, W. D. (2016). Normlessness, Anomie, and the Emotions. Sociological Forum, 31(2), $465-486$. doi:10.1111/socf.12253

Tian, X., \& Zou, X. (2018). Capturing Size and Intensity Changes of Hurricanes Irma and Maria (2017) from Polar-Orbiting Satellite Microwave Radiometers. Journal of the Atmospheric Sciences, 75(8), 2509-2522. doi:10.1175/JAS-D-17-0315.1 
Tsugawa, S. O. H., \& Ohsaki, H. (2017). On the Relation Between Message Sentiment and Its Virality on Social Medisa. Social Network Analysis and Mining, 7(1), 1-19. doi:10.1007/s13278-017-0439-0

Wang, H., \& Wang, S. (2008). Ontology for data mining and its application to mining incomplete data. Journal of Database Management, 19(4), 81-90. doi:10.4018/jdm.2008100105

Wilson, T. D., Wheatley, T., Meyers, J. M., Gilbert, D. T., \& Axsom, D. (2000). Focalism: A source of durability bias in affective forecasting. Journal of Personality and Social Psychology, 78(5), 821-836. doi:10.1037/00223514.78.5.821 PMID:10821192

Zhang \& Zhang. (2018). Research on the Influencing Factors of Knowledge Contribution Behavior Intention of Users in Social Q\&A Community Based on Grounded Theory. Journal of the China Society for Scientific and Technical Information, 37(10), 1034-1045.

Zhao, Y., \& Bing, Q. (2010). Text Emotion Analysis. Journal of Software, 21(08), 1834-1848. doi:10.3724/ SP.J.1001.2010.03832

Zhou, Q., \& Jing, M. (2020). Detecting Expressional Anomie in Social Media via Fine-grained Content Mining. Journal of Database Management, 31(1), 1-19. doi:10.4018/JDM.2020010101

Chunnian Liu is a professor in College of Management at Nanchang University. She holds a Ph.D. from the Wuhan University, China. Her primary research activities address the Emergency Information management, her research seeks to understand issues related to Emergency information systems integration, the media public opinion monitoring and open innovations. She has published with a variety of journals, including Frontiers in Psychology, Applied ecology and environmental research, as well as in conference proceedings, including those of the international conference on information systems.

Qi Tian is a Ph.D. Candidate in College of Management at Nanchang University. His interests include nature language processing, emergency information management, and data mining.

Mengqiu Chen is a Master Candidate in College of Management at Nanchang University. Her interests include emergency information management and data mining. 